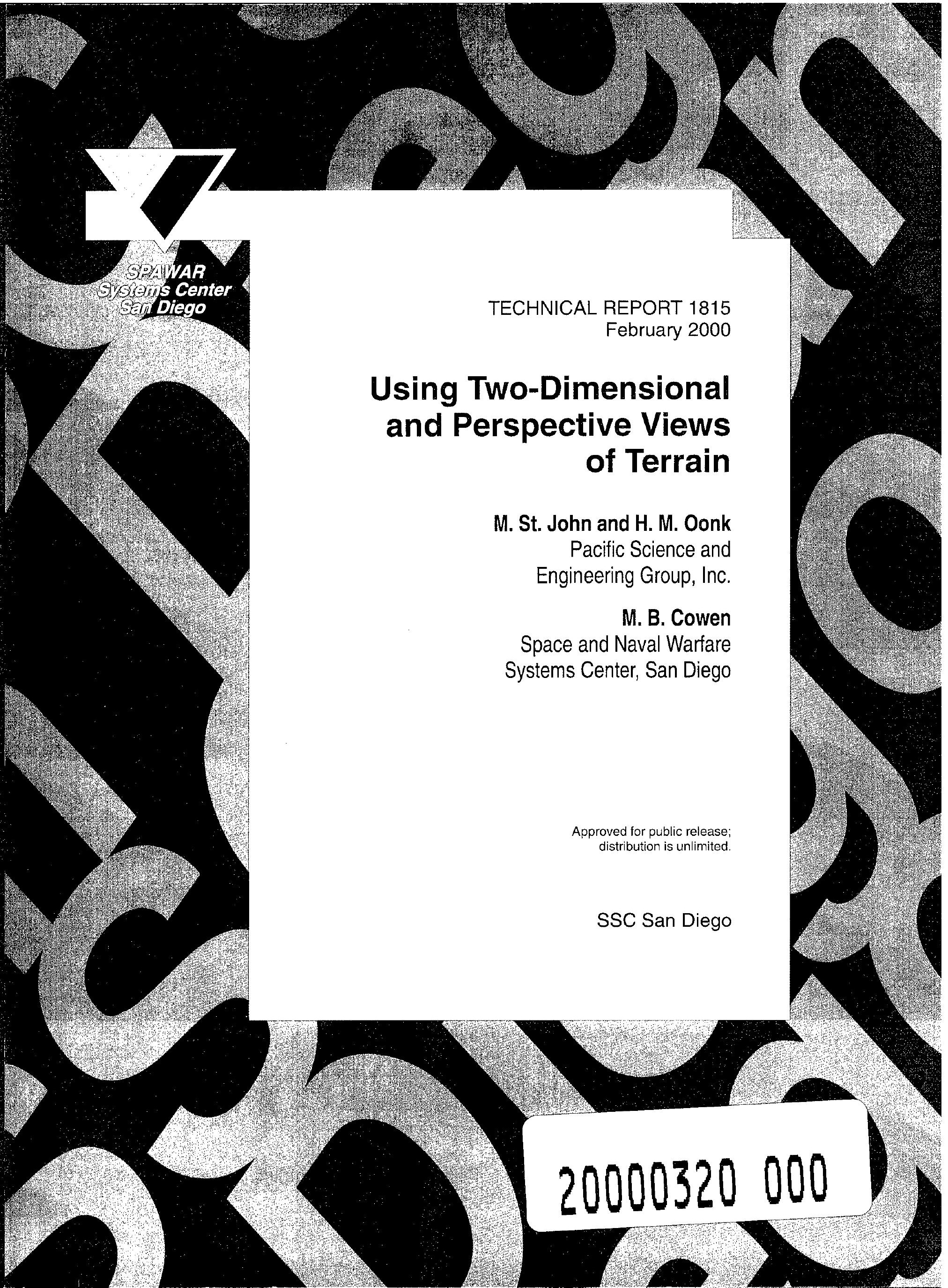


TECHNICAL REPORT 1815

February 2000

\title{
Using Two-Dimensional and Perspective Views of Terrain
}

\author{
M. St. John and H. M. Oonk \\ Pacific Science and \\ Engineering Group, Inc. \\ M. B. Cowen \\ Space and Naval Warfare \\ Systems Center, San Diego
}

SSC San Diego
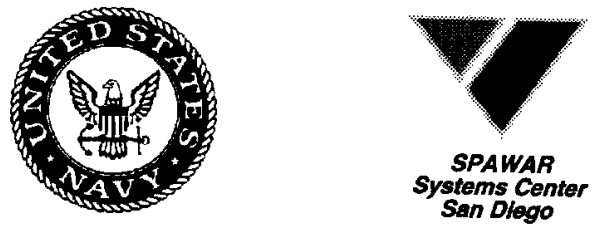

SSC San Diego

San Diego, CA 92152-5001 


\section{SSC SAN DIEGO \\ San Diego, California 92152-5001}

\section{ADMINISTRATIVE INFORMATION}

The work described in this report was performed for the Collaborative Technologies Project Team (D44210) of the Simulation and Human System Technology Division (D44) of the Command and Control Department (D40) of the Space and Naval Warfare Systems Center by Pacific Science and Engineering Group, Inc., as Delivery Order 58 under contract N66001-96-D-0048. Funding was provided by the Office of Naval Research (ONR 342) under program element 0602233N. This report covers work from October 1998 to December 1999.

Released by

R. J. Smillie, Head

Collaborative Technologies

Branch
Under authority of J. D. Grossman, Head Simulation and Human Systems Technology Division

\section{ACKNOWLEDGMENTS}

The authors would like to thank and acknowledge the following individuals who reviewed this report for technical accuracy: Dr. Robert Smillie and Mr. Orv Larson from the Space and Naval Warfare Systems Center, San Diego, Mr. David Dickason from the Navy Personnel Research and Development Center, Dr. Samuel Landau from the Fleet ASW Training Center, San Diego, and Dr. Dewey Kribs from Instructional Science and Development Inc. 


\section{EXECUTIVE SUMMARY}

The use of three-dimensional (3-D) perspective views on flat screens for military command and control tasks is accelerating. The question is when and how to use these displays effectively. We report the results of three experiments to test the hypotheses that 3-D displays are useful for understanding object shape, but two-dimensional (2-D) displays are more useful for understanding relative positions of objects. We tested this hypothesis using terrain stimuli. Participants viewed a 7-by 9-mile piece of terrain in 3-D from a 45-degree angle, a 90-degree angle, or in 2-D as a topographic map. In Experiment 1, participants chose the correct ground-level view from among four alternatives. In Experiment 2, participants judged whether the position of one location was visible from another location, or obstructed by intervening terrain. In Experiment 3, participants judged which of two locations was higher. We found that participants were faster and more accurate in selecting the correct terrain shape with the 3-D views, but were more accurate in selecting the higher terrain location with the $2-\mathrm{D}$ views. 


\section{CONTENTS}

EXECUTIVE SUMMARY ............................................................................................... ii

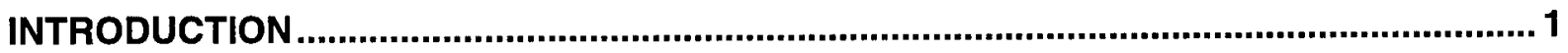

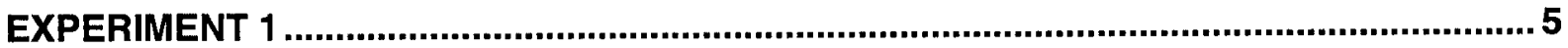

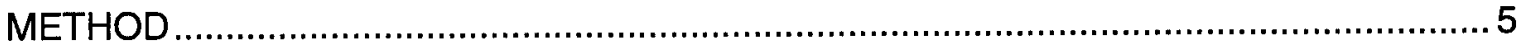

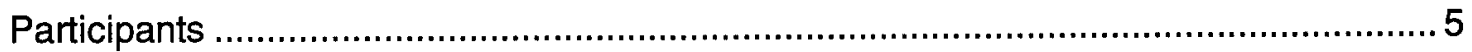

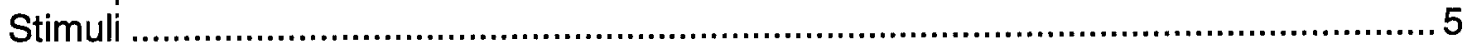

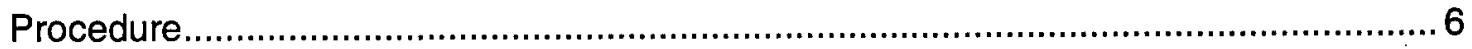

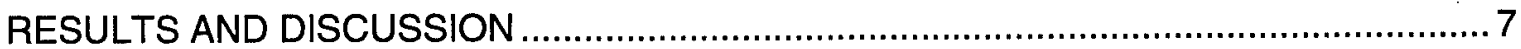

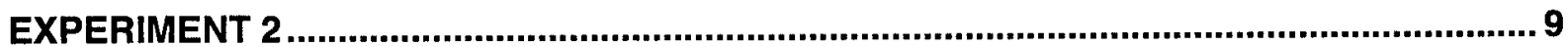

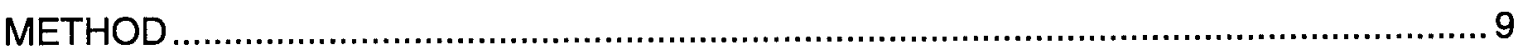

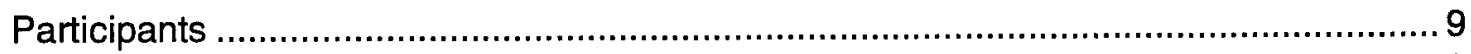

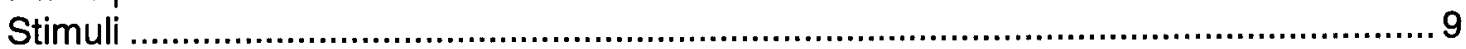

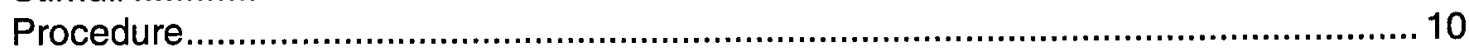

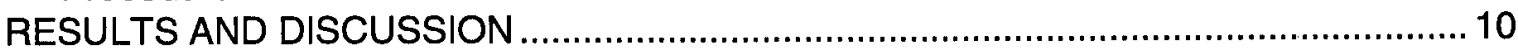

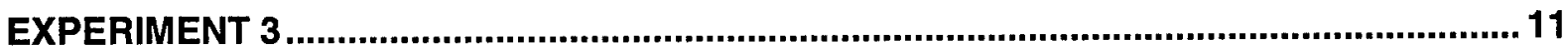

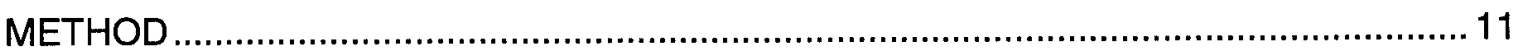

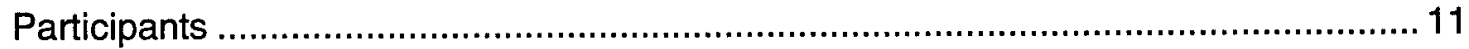

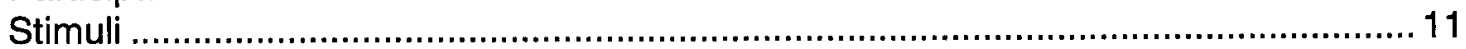

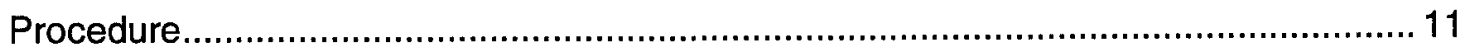

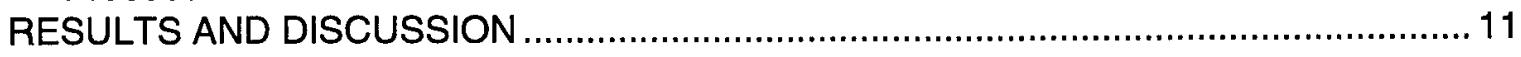

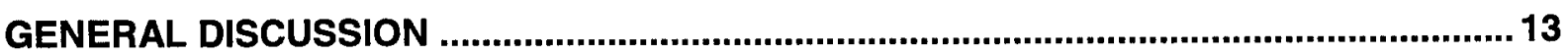

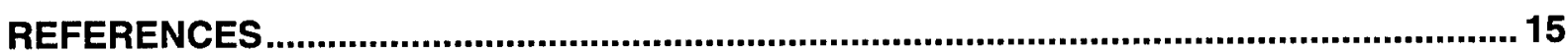




\section{Figures}

1. 2-D and 3-D views of an example block and ball used in St. John and Cowen (1999).......... 2

2. 3-D 45-degree view trial in Experiment 1. Participants visualize standing on ground at the white cross and looking to southeast; they must then select the correct ground-level view. Correct answer is top-right.

3. 90-degree view and topographic view of the same terrain shown in figure $2 \ldots \ldots \ldots \ldots \ldots \ldots \ldots . . . . . . . . . .7$

4. reaction times and proportions correct on Four-Corners task. Error bars show one standard error. .................................................................................................. 7

5. Example stimulus from Experiment 2 (shown with 3-D 45-degree view). ......................... 9

6. Response times and proportions correct on A-See-B task. Error bars indicate one standard error.

7. Response times and proportions correct on A-High-B task. Error bars show one standard error 


\section{INTRODUCTION}

Many military command and control tasks require quick apprehension of objects in a three-

dimensional (3-D) space. For example, anti-air warfare officers need to understand a complex 3-D environment populated with aircraft, surface assets, sensor locations, and anti-aircraft platforms. Consoles that display data in 3-D seem to provide a natural, and increasingly affordable, solution to these needs. However, the empirical evidence supporting the use of 3-D displays is decidedly mixed, and Andre and Wickens (1995) caution that sometimes "users want what's not best for them." Across an array of tasks, many studies have found benefits for a 3-D perspective over a two-dimensional (2-D) perspective (Andre et al., 1991; Bemis, Leeds, and Winer, 1988; Burnett and Barfield, 1991; Ellis, McGreevey, and Hitchcock 1987; Haskell and Wickens, 1993; and Van Breda and Veltman, 1998). Other studies have found rough parity (Wickens et al., 1996), and still other studies have found 2-D superior to 3-D (Boyer et al., 1995; O'Brien and Wickens, 1997; Ware and Lowther, 1997). The various tasks and displays make synthesis difficult, and in some cases, results may show the human performance demands needed to perform a task rather than the nature of the displays themselves.

Our strategy was to consider the basic qualities of 2-D and 3-D views, what types of information those qualities best convey, and which tasks require that information. We believe that the main advantage of 3-D perspective views is the capability to easily convey the shape of complex objects because it integrates the three dimensions into a single view and provides natural depth cues such as perspective, shading, and occlusion. For instance, perspective occurs when images of same-sized objects shrink as they recede into the distance and that shrinkage acts as a cue to place them in depth. The main disadvantage of 3 -D perspective views seems to be the ambiguity and distortion of angles and distances, caused by foreshortening, which make precise judgments of distance and relative position difficult (St. John and Cowen, 1999). Foreshortening, an effect of perspective, occurs when distances to objects in the foreground are shortened when not lying in a plane perpendicular to the line of sight. These problems are exacerbated when objects are small and separated by empty space (e.g., in air traffic control) because added depth cues will not overcome the effects of foreshortening.

In an earlier study (St. John and Cowen, 1999), we tested the hypothesis that 3-D perspective views lead to better object understanding than $2-\mathrm{D}$ views, and 2-D views lead to better relative position judgments than 3-D views. We created simple 3-D block shapes that were rendered as a 3-D perspective view or as a set of 2-D views (see figure 1 ). 

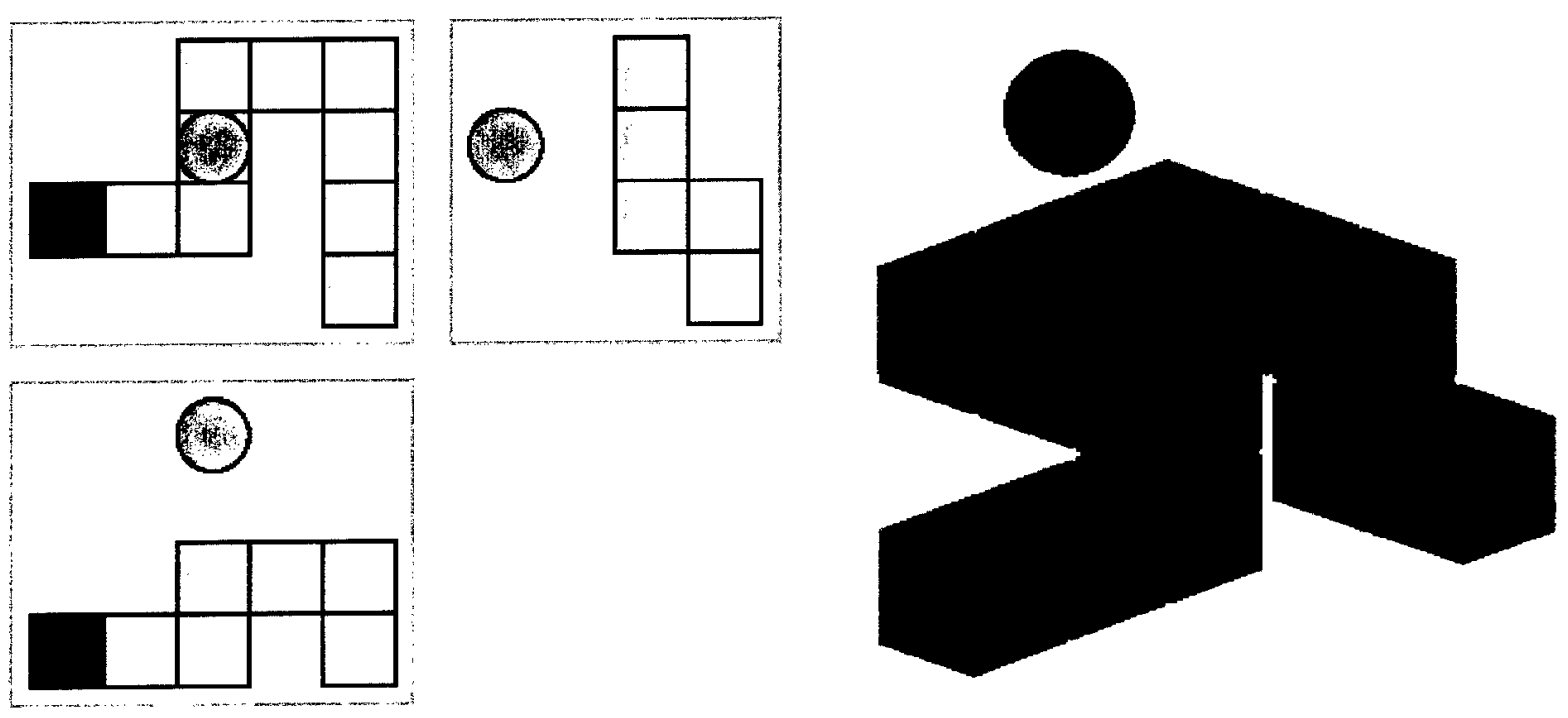

Figure 1. 2-D and 3-D views of an example block and ball used by St. John and Cowen (1999).

In one test of shape understanding, participants were shown a set of 2-D views or a 3-D view of a block, and they were asked to pick out the block from among three real blocks laid out on a table. We found that participants were faster and more accurate using the 3-D view than the 2-D views, even when blocks were rotated 90 degrees.

In a test of relative position judgments, participants were shown a 2-D or 3-D view of a block with a ball suspended above it and were asked to indicate which cube of the block lay directly beneath the ball. Note that the location is ambiguous in the 3-D view in figure 1. Accordingly, we provided two $3-\mathrm{D}$ views or three $2-\mathrm{D}$ views (top, front, and side) to help locate the ball's position. Participants were far faster using the 2-D views.

After correctly locating the cube beneath the ball, participants had to navigate the number of moves in "cubes" in each direction (i.e., north, south, east, west, up, and down) to move from the red cube to the ball. In the example in figure 1, you must move 3 up, 2 east, and 1 north to get from the red cube to the ball. For this task, we found that participants were faster and more accurate using the $2-\mathrm{D}$ views than the $3-\mathrm{D}$ view. We concluded that the $2-\mathrm{D}$ views were better than the 3 -D views for understanding the relative position of the ball to the block, but the 3-D view was clearly better for understanding the shapes of these simple blocks. We surmised that using 2-D views to understand the block's shape is inferior because the distinct 2-D views must be integrated, which takes time.

The block stimuli were chosen for their simplicity and generality to test the hypothesis minimizing confounding variables. The simple block stimuli were composed of cubes so that all angles were right angles and all lengths cube units. These features could be used to compensate for distortions in the 3-D display. For example, no matter how an angle might have appeared in the view, it was known to be a right angle. The block's regular angles and lengths help depth perception in a 3-D perspective display. How might the results generalize to more complex and natural stimuli?

Physical terrain does not have right angles or unit lengths. It is free form, and users will benefit little from familiarity with other real-world terrain. We would expect, therefore, that the object understanding benefits of 3-D views would diminish for free-form stimuli such as terrain.

Nonetheless, we expect that the basic dichotomy of 3-D for shape understanding and 2-D for judging relative positions will be maintained. In three experimental tasks, we tested the hypothesis that 3-D 
views are better for terrain understanding, and 2-D views are better for judging the relative position of two terrain locations.

Before proceeding, it is worth discussing how we chose the 2-D and 3-D representations that we used in these experiments. There is some variety among representations reported in the literature. It is probably best to think of 2-D and 3-D displays as "natural concepts" (Rosch, 1973; Wittgenstein, 1958) that have no defining necessary or sufficient conditions. Instead, they share a set of family resemblances. For 3-D perspective view displays, primary resemblances that are shared by most representations are shading and oblique views that show all three dimensions of an object (e.g., a view from 30,45 , or 60 degrees). For 2-D views, the primary resemblance is a right-angle view (e.g., a view from 0,90 , or 180 degrees) that shows only two dimensions. However, it is possible to have a 3-D view that contains a right-angle view with shading: the 90-degree (top-down) 3-D view.

Aside from family resemblances, it is important that representations be useful and effective. For example, for representing terrain in a 2-D view, we chose to use topographic lines to represent altitude in a top-down view rather than using a top-down view plus a side view. We also chose to color the topographic lines to represent different altitudes rather than labeling the lines with numeric altitudes. Our choices were driven by the desire to create good displays that are representative of 2-D and 3-D real-world displays. We chose representations to find a performance crossover among tasks such that the same representations would be better for some tasks and worse for others. 


\section{EXPERIMENT 1}

In Experiment 1, we tested the hypothesis that 3-D is better for terrain understanding. Each participant viewed a 7-by 9-mile piece of terrain viewed in 3-D from a 45-degree angle, in 3-D from a 90-degree angle, and in 2-D as a topographic map. Their task was to visualize standing in the center of the map, look to a specified corner of the map, and then choose the correct ground-level view from among four alternatives (the "Four-Corners" task). We predicted that the 45-degree view (see figure 2) would convey the shape of the terrain most effectively and would best support visualizing the ground-level view. This task resembles the mental rotation task used by St. John and Cowen (1999), who found a substantial 3-D benefit. In both cases, participants must visualize how an object would look when viewed from a different angle. This task required an understanding of the basic layout of the terrain: the shapes of terrain features, and their rough layout. No precision was required.

\section{METHOD}

\section{Participants}

The participants were 18 civilians employed at a local engineering company or students from local universities who were paid for their participation.

\section{Stimuli}

The participants viewed three conditions: (1) a 45-degree view, (2) a 90-degree view, and (3) a topographic view. Thirteen 7- by 9-mile U.S. Geological Survey Digital Elevation models created the stimuli. This size terrain is similar to that found on standard 1:50,000 scale military maps. These models were processed through MicroDem to create elevation bitmaps. Separate renderings were made for a 3-D 45-degree view, a 3-D 90-degree view, and a topographic view. The topographic maps were created in MicroDem by drawing iso-altitude contour lines on the map. Unlike typical hiking maps, which use numbers to depict altitude, the contour lines were coloredcoded to indicate altitude. The program assigned purple for the lowest altitude on the map, various colors throughout the color spectrum for intermediate altitudes, and assigned red for the highest altitude on the map.

The 3-D 45- and 90-degree views were created by importing the elevation bitmaps into 3D Studio. The camera had a 90-degree field of view and a wide-angle $18 \mathrm{~mm}$ lens. An omnilight source (the sun) was placed directly west of the center of the map and at 50 degrees above ground level from the center of the map. Note that the alternative to having the light source at 90 degrees above the center of the map creates an ambiguous image in which changes in altitude are discernable, but the direction of change is not. For example, a ridge appears ambiguously as a ridge or a canyon. Having the light source too low toward the horizon creates shadows that are too large and obscure too much terrain. Having the light source directly behind the camera along the line of sight creates a flat-looking landscape that is difficult to understand, and having the light source directly opposite the camera creates shadows that obscured much of the visible terrain. Therefore, we choose the light source as roughly 50 degrees above ground level and 90 degrees to the left or right of the camera for optimal depth perception. 

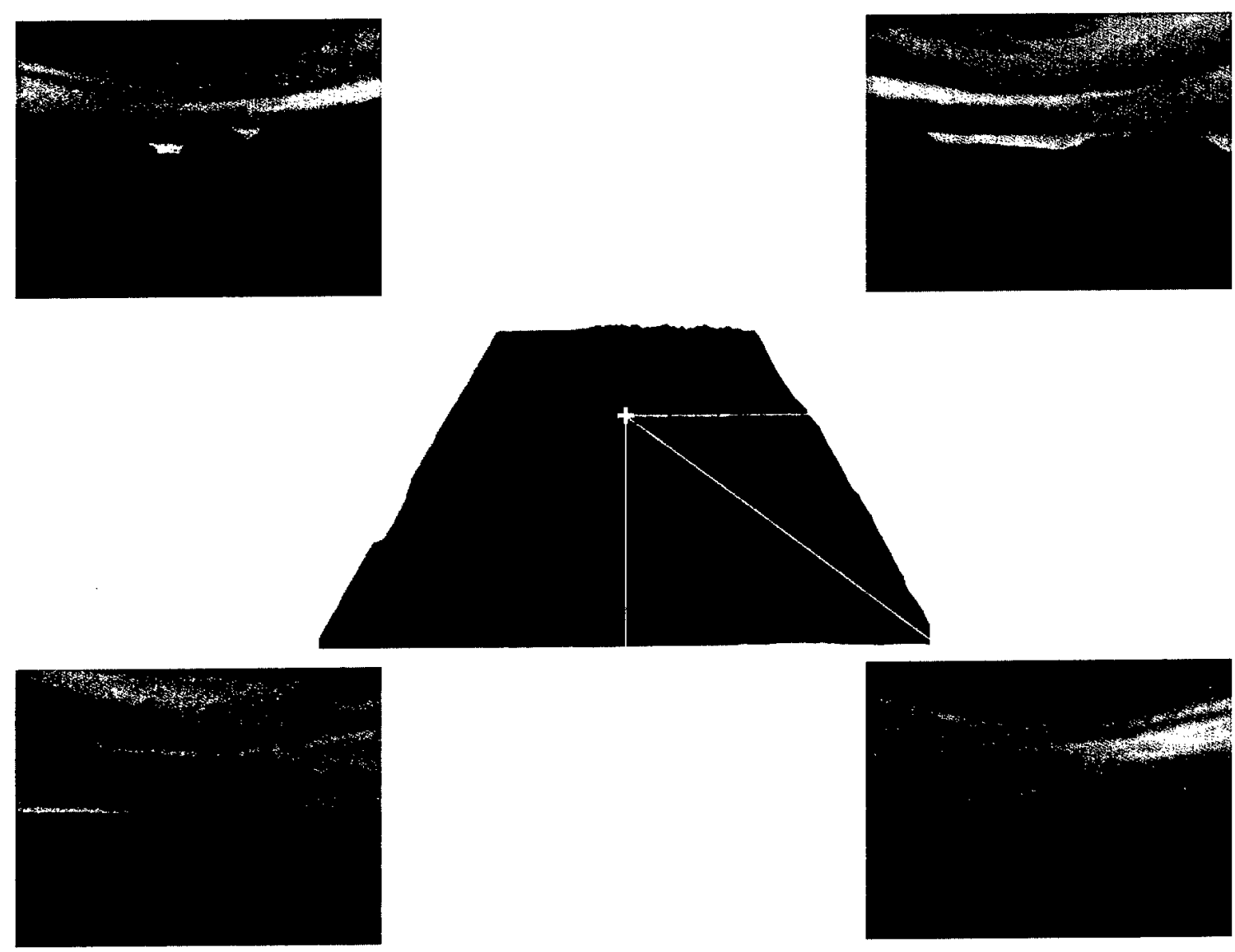

Figure 2. 3-D 45-degree view trial in Experiment 1. Participants visualize standing on ground at the white cross and looking to southeast; they must then select correct ground-level view. Correct answer is top-right.

For the 3-D 90-degree views, the camera was suspended 3.5 miles directly over the center of the map-high enough to view the entire map. For the 3-D 45-degree views, the camera was to the south of the map so that the entire map was visible, maintaining a 45-degree angle between ground level and the line of sight to the center of the map.

The ground level views were created in 3D Studio, visualizing what one would see by standing at the center of the map and looking out to each of the four corners of the map. The ground views were placed in a random order around the map. Figure 2 shows an example trial containing a map having the 3-D 45-degree view and the four ground-level views. Figure 3 shows the 3-D 90-degree view and the 2-D topographic view of the same terrain. Two stimuli were created for each terrain map by placing a white cross at the center of the terrain and designating different corners to visualize.

\section{Procedure}

The participants viewed all three conditions (e.g., 45-degree, 90-degree, topographic) in a counter-balanced order. The 26 stimuli were presented one at a time on a 17 -inch monitor. Participants viewed the central map and visualized the ground-level view for the designated direction. They then chose one of the four ground-level views by using a mouse to click the appropriate on-screen button. Reaction times for correct trials and errors were recorded, and 
correct/incorrect feedback was provided. Following each response, whether correct or incorrect, the computer advanced to a pause screen. When ready, participants continued to the next trial by clicking an on-screen "next" button.
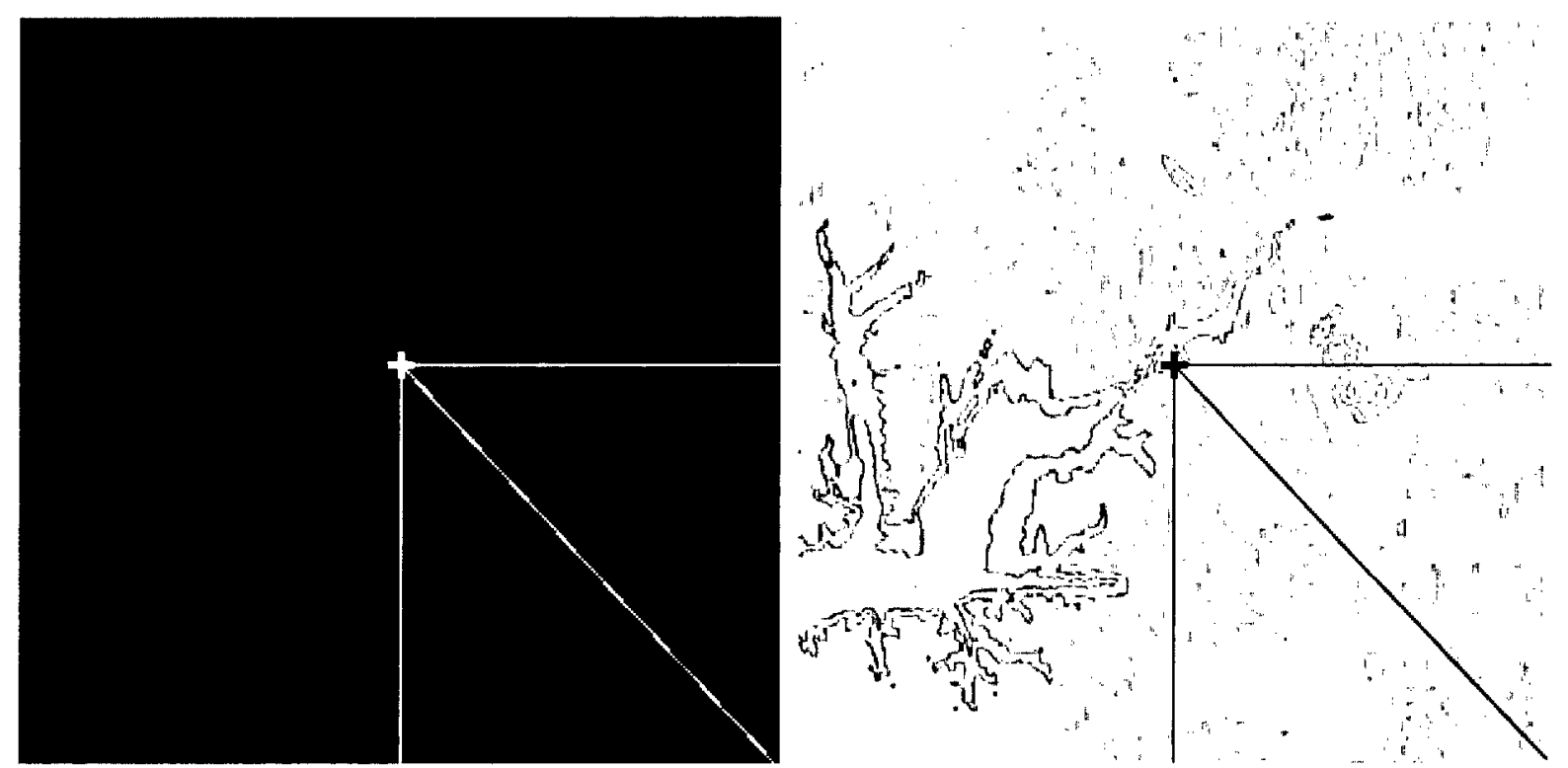

Figure 3. 90-degree view and topographic view of same terrain shown in figure 2.

\section{RESULTS AND DISCUSSION}

Response times for correct trials were averaged, and percent correct scores were calculated (see figure 4). Note that this task was very difficult for all the views. Nonetheless, participants were faster with the 45 - and 90 -degree views $(\underline{\mathrm{F}}(2,34)=6.60, \underline{\mathrm{p}}<.005)$ and slightly more accurate (i.e., approached statistical significance) with the 45-degree view compared to the topographic view $(\underline{\mathrm{t}}(17)=1.88, \underline{\mathrm{p}}<.08)$.
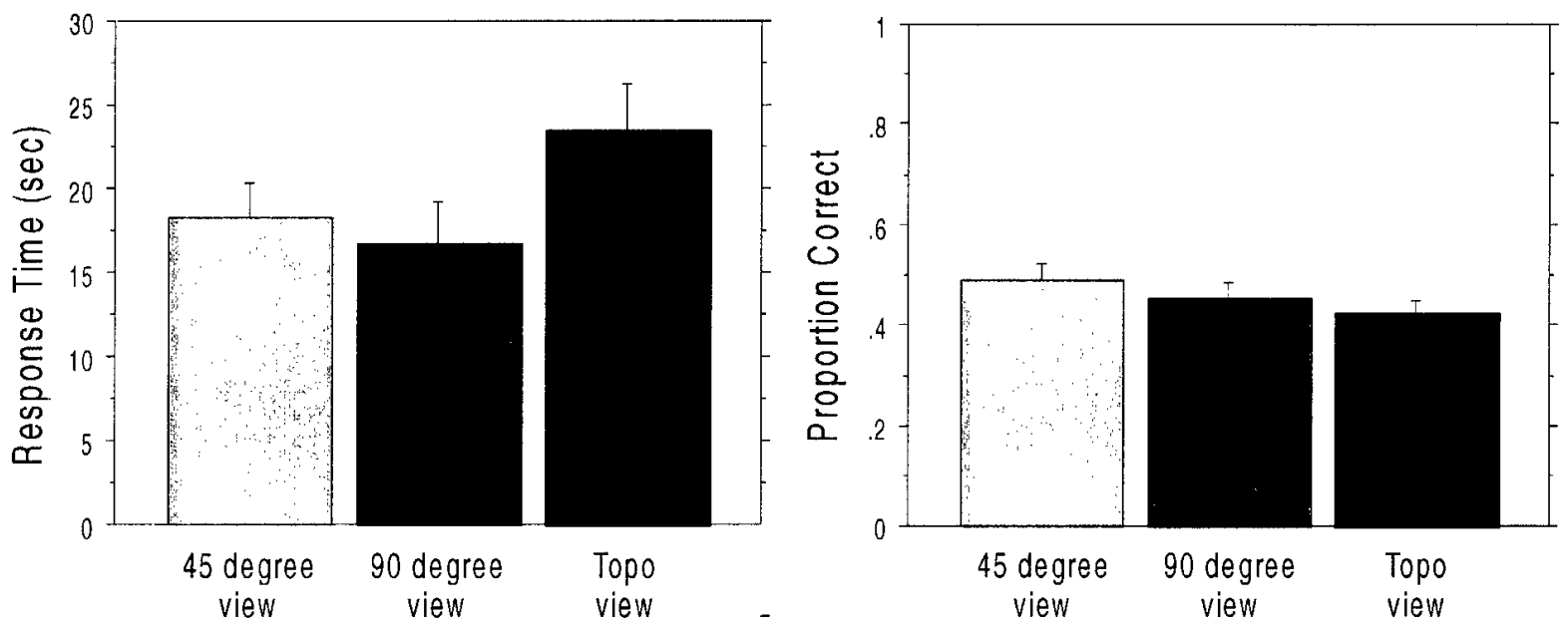

Figure 4. Reaction times and proportions correct on Four-Corners task. Error bars show one standard error. 
These results support our hypothesis that the 3-D views are better for understanding the shape and layout of terrain. In the 2-D topographic view, altitude is depicted symbolically as colored contour lines, which must be mentally constructed into 3-D shapes.

In the 45-degree view, the shape of the terrain is represented as the actual shape of the terrain using a spatial dimension (as seen from 45 degrees above the horizon) as well as by shadows as a cue to depth and height. Interestingly, performance using the 90-degree view was as good as performance using the 45-degree view although the 90-degree view does not represent height using a spatial dimension. This result seems counter to our hypothesis that perspective views are better for terrain understanding since the 90-degree view uses the top-down viewing angle usually found in maps.

However, it may be best to understand the 90-degree view as an interesting compromise between 2-D and 3-D views. Similar to maps where the viewing angle is straight down, the 90 -degree view represents latitude and longitude faithfully (except that the 90 -degree view is still a perspective, oblique view with vanishing points around the horizon). However, the 90-degree view is similar to the 3-D perspective view in that it has 3-D depth cues such as shadows, which seem to play a major role in terrain visualization. 


\section{EXPERIMENT 2}

In Experiment 2, we further tested the hypothesis that 3-D views are better than 2-D views for understanding the shape of terrain by judging whether one ground location was visible from another ground location or obstructed by an intervening hill. We identified two points on a piece of terrain, and we asked participants if they would be able to see point $B$ if they were standing at point $A$ (the "A-See-B" task). Because this task involves the relationship between two points, one might suspect it to be a relative position task. However, the task was designed to assess the shape of the terrain between the two points, and to determine whether or not the shape blocks the view between those two points.

\section{METHOD}

\section{Participants}

The participants were 27 students from local universities who were paid for their participation.

\section{Stimuli}

The stimuli were created from the same 13 models of terrain that were used in Experiment 1. Twenty-six stimuli were created (two from each of the 13 models of terrain). To create a stimulus, we plotted two points on the terrain. The two points were chosen randomly from different quadrants of the terrain, and they were labeled $\mathrm{A}$ and $\mathrm{B}$ (see figure 5). Each stimulus was rendered in 3-D from a 45-degree angle, in 3-D from a 90-degree angle, and as a 2-D topographic map. The renderings were created in the same way as described in Experiment 1.

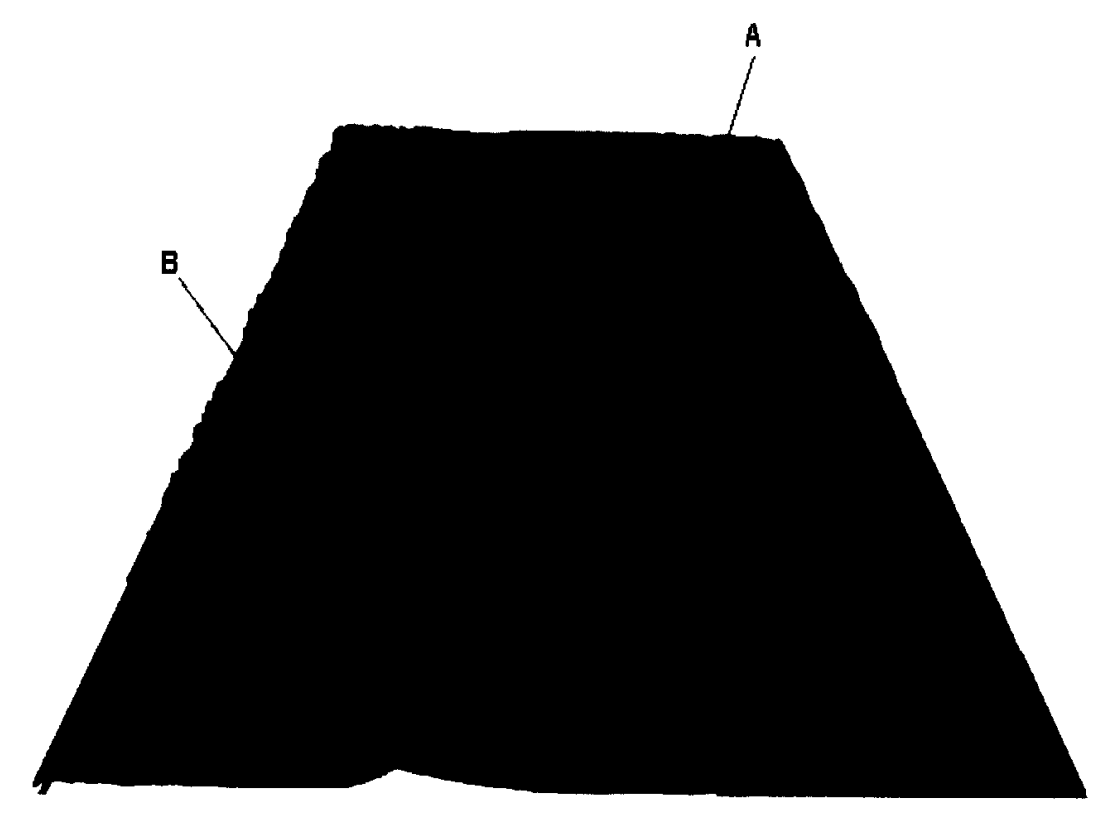

Figure 5. Example stimulus from Experiment 2 (shown with 3-D 45-degree view). 


\section{Procedure}

Because of the simple nature of this task, there was a concern about participants becoming too familiar with our maps. Therefore, participants performed in only one of the three conditions: a 45-degree view, a 90-degree view, or a topographic view. The 26 stimuli were presented on a $17-$ inch monitor. Participants were asked to determine whether they could see point B if they were standing at point $A$. Participants were shown one stimulus at a time. They responded by clicking an on-screen button for True (A can see B) or False (A cannot see B). Response times were recorded, and feedback was provided. Following each response, whether correct or incorrect, the computer advanced to a pause screen. When ready, participants continued to the next trial by clicking an onscreen "next" button.

\section{RESULTS AND DISCUSSION}

The A-See-B task was less difficult than the Four-Corners task, having a mean response time of 5.8 seconds and a mean accuracy of 81 percent. Overall, the three viewing conditions produced significantly different response times, $\mathrm{F}(2,21)=4.10, \mathrm{p}<.03$ (see figure 6 ). As predicted, the 3-D 45 -degree view was reliably faster than the 2 -D topographic view, $\underline{t}(14)=2.68, \mathrm{p}<.02$, and the 3 -D 90 degree view was faster than the 2-D topographic view, but this difference was not statistically significant, $\underline{\mathrm{t}}(14)=1.82, \mathrm{p}<.09$. The accuracy (percent correct) scores did not differ significantly, but were in the predicted direction, with the 3-D views being more accurate than the 2-D topographic view. In short, comprehending whether or not a terrain shape blocks the view between two points on a landscape was easier using 3-D views.
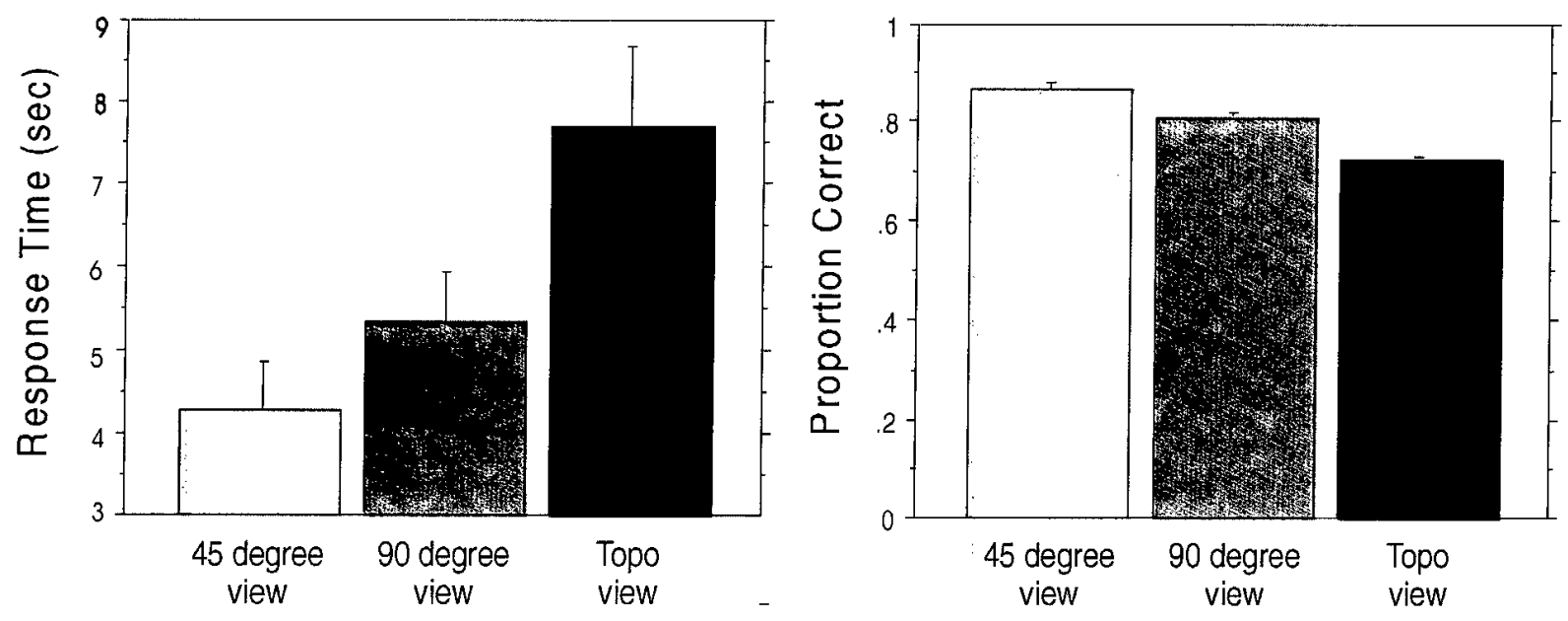

Figure 6. Response times and proportions correct on A-See-B task. Error bars indicate one standard error. 


\section{EXPERIMENT 3}

In Experiment 3, we tested the hypothesis that 2-D views are better for judging the relative position of two terrain locations. Again, participants viewed a 7-by 9 -mile piece of terrain containing two identified points in 3-D from a 45-degree angle, in 3-D from a 90-degree angle, or in 2-D as a topographic map. Participants judged which point was higher. This task required participants to judge the relative position of two points. Our hypothesis predicted that the 2-D topographic map would produce the best performance.

\section{METHOD}

\section{Participants}

The participants were 27 civilians employed at a local military research and development center.

\section{Stimuli}

The stimuli were created from the same 13 models of terrain that were used in Experiments 1 and 2. Twenty-six stimuli were created (two from each of the 13 models of terrain). To create a stimulus, we plotted two points on the terrain. The renderings were created in the same way as described in Experiment 2. The two points were chosen randomly from different quadrants of the terrain, and they were labeled A and B (see figure 5). Each stimulus was rendered in 3-D from a 45-degree angle, in 3-D from a 90-degree angle, and as a 2-D topographic map.

\section{Procedure}

Similar to the procedure in Experiment 2, participants performed in only one of the three conditions: (1) a 45-degree view, (2) a 90-degree view, or (3) a topographic view. The 26 stimuli were presented on a 17-inch monitor. Participants were asked to pick which of the two points, A or B, was higher (the "A-High-B" task). Participants were shown one stimulus at a time; they responded by clicking an on-screen button for A or B. Response times were recorded, and feedback was provided. Following each response, whether correct or incorrect, the computer advanced to a pause screen. When ready, participants continued to the next trial by clicking an on-screen "next" button.

\section{RESULTS AND DISCUSSION}

Although those in the topographic view condition seem to take longer, no statistically significant differences were found for response times (see figure 7). For accuracy, however, participants were significantly more accurate with the topographic view than the 45-degree view $(\underline{t}(16)=3.12, \underline{p}<$ $.01)$ or the 90 -degree view $(\mathrm{t}(16)=5.43, \mathrm{p}<.0001)$.

As figure 7 shows, there seems to be a small speed-accuracy trade-off in the data, suggesting that the greater accuracy for the topographic view was caused by slower, more careful response times. However, since the variability of response time data was high and there were no statistically significant differences, the trade-off is of only minor concern. 

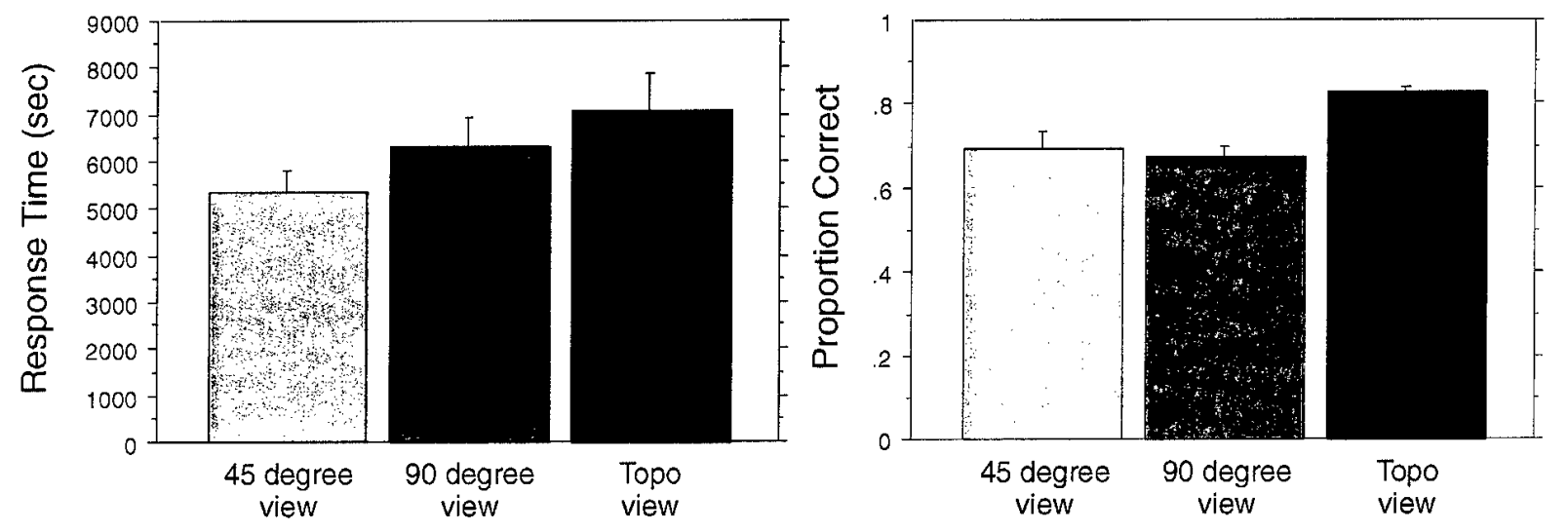

Figure 7. Response times and proportions correct on A-High-B task. Error bars show one standard error.

The greater accuracy of the topographic view supports our hypothesis that relative position judgments are easier to perform with 2-D top-down views than 3-D perspective views. In this case, relative height was easier to determine in the topographic view because height was rendered by the color of contour lines. Participants only needed to determine the color of the nearest contour line for each point and then compare colors. Conversely, in the 45-degree view, height is conveyed by shadows and by elevation. However, elevation in the 45-degree view is distorted in that large vertical distances in the background seem very small. Additionally, shadows are an unreliable height cue because flat ground may have a subtle, but significant, rise in gradient from one side of a view to another. Therefore, hills that seem to rise equally high above a plain may have significantly different elevations.

The 90-degree view does not suffer from the distortions of distance that are inherent in the 45-degree view because a spatial dimension does not represent height. Height is only represented by shadows. The 90-degree view, therefore, falls prey to the same problems with using shadows to judge height as the 45-degree view. The topographic view, of course, does not represent height using a spatial dimension either, but it does explicitly represent height by using color codes. In summary, participants using the 2-D view judged the relative height of two terrain locations more accurately because height was explicitly depicted. 


\section{GENERAL DISCUSSION}

Our strategy was to step back from more applied studies of 3-D displays to consider the fundamental capabilities and limits of 2-D and 3-D views, and to ask what tasks best fit those capabilities. The 3-D views are compelling because they integrate all three dimensions into a single view and represent space "naturally." Yet, this natural representation is fraught with ambiguity. Using renderings of simple blocks and terrain, St. John and Cowen (1999) found that each view can be useful: 3-D for understanding object shape, and 2-D for understanding relative position of two or more objects. Here, we extended this finding to free-form terrain stimuli. The terrain tasks we chose to test this hypothesis, however, have not produced the dramatic results we had obtained with the original block stimuli. Nonetheless, the hypothesis seems correct. We currently are working to develop several additional terrain tasks that might corroborate and extend these findings.

These findings, both for regularly shaped simple blocks and now for free-form terrain, may have important implications of the design of military command and control consoles (and civilian displays as well). Although more research is needed, our present findings together with St. John and Cowen (1999) suggest that 3-D perspective views should be used for recognizing the general shapes of military assets, cultural features, and terrain landscape. For tasks that require more precise judgments of relative position (e.g., height and distance), however, we suggest using 2-D views. 


\section{REFERENCES}

Andre, A. D. and C. D. Wickens. 1995. "When Users Want What's Not Best For Them," Ergonomics in Design (Oct), pp. 10-14.

Andre, A. D., C. D. Wickens, L. Moorman, and M. M. Boschelli. 1991. "Display Formatting Techniques for Improving Situation Awareness in Aircraft Cockpit," International Journal of Aviation Psychology, vol. 1, pp. 205-218.

Bemis, S. V., J. L. Leeds, and E. A. Winer. 1988. “Operator Performance as a Function of Types of Display: Conventional versus Perspective, Human Factors, vol. 30, pp. 163-169.

Boyer, F., M. Campbell, P. May, D. Merwin, and C. D. Wickens. 1995. "Three Dimensional Displays for Terrain and Weather Awareness in the National Airspace System." Proceedings of the Human Factors and Ergonomics Society $39^{\text {th }}$ Annual Meeting (pp. 6-10). Santa Monica, CA. Human Factors and Ergonomics Society.

Burnett, M. S. and W. Barfield. 1991. "Perspective versus Plan View Air Traffic Control Displays: Survey and Empirical Results." Proceedings of the Human Factors Society $35^{\text {th }}$ Annual Meeting (pp. 87-91). Santa Monica, CA. Human Factors and Ergonomics Society.

Ellis, S. R., M. W. McGreevey, and R. J. Hitchcock. 1987. "Perspective Traffic Display Format and Airline Pilot Traffic Avoidance," Human Factors, vol. 29, pp. 371-382.

Haskell, I. D. and C. D. Wickens. 1993. "Two and Three-Dimensional Displays for Aviation: A Theoretical and Empirical Comparison," International Journal of Aviation Psychology, vol. 3, pp. 87-109.

O'Brien, J. V. and C. D. Wickens. 1997. "Free Flight Cockpit Displays of Traffic and Weather: Effects of Dimensionality and Data Base Integration." Proceedings of the Human Factors and Ergonomics Society $41^{\text {st }}$ Annual Meeting (pp.18-22). Santa Monica, CA. Human Factors and Ergonomics Society.

Rosch, E. 1973. “Natural Categories," Cognitive Psychology, vol. 4, pp. 328-350.

St. John, M., and M. B. Cowen. 1999. "Use of Perspective View Displays for Operational Tasks. Technical Report 1795. Space \& Naval Warfare System Center, San Diego, CA.

http://www.spawar.navy.mil/sti/publications/pubs/tr/1795/tr1795.pdf (February 2000)

Van Breda, L. and H. S. Veltman. 1998. "Perspective Information in the Cockpit as a Target Acquisition Aid," Journal of Experimental Psychology: Applied, vol. 4, pp. 55-68.

Ware, C. and K. Lowther. 1997. "Section Using a One-Eyed Cursor in a Fish Tank VR Environment," ACM Transactions on Computer-Human Interaction, vol. 1, 309-322.

Wickens, C. D., C. Liang, T. Prevett, and O. Olmos. 1996. "Electronic Maps for Terminal Area Navigation: Effects of Frame of Reference and Dimensionality," International Journal of Aviation Psychology, vol. 6, 241-271.

Wittgenstein, L. 1958. Philosophical Investigations. 2nd ed. Blackwell Publishers, Oxford, U.K. 
Public reporting burden for this collection of information is estimated to average 1 hour per response, including the time for reviewing instructions, searching existing data sources, gathering and maintaining the data needed, and completing and reviewing the collection of information. Send comments regarding this burden estimate or any other aspect of this collection of information, including suggestons for reducing this burden, to Washington Headquarters Services, Directorate forlnformation Operations and Reports, 1215 Jefferson Davis Highway, Suite 1204 , Arlington, VA $22202-4302$. and to the Office of Management and Budget, Paperwork Reduction Project (0704-0188), Washington, DC 20503. 1. AGENCY USE ONLY (Leave blank) 2. REPORT DATE

February 2000 3. REPORT TYPE AND DATES COVERED

4. TITLE AND SUBTITLE

USING TWO-DIMENSIONAL AND PERSPECTIVE VIEWS OF TERRAIN

6, AUTHOR(S)

M. St. John and H. M. Oonk

M. B. Cowen

Pacific Science and Engineering Group, Inc. SSC San Diego

Final: October 1998 to December 1999

7. PERFORMING ORGANIZATION NAME(S) AND ADDRESS(ES)

SSC San Diego

San Diego, CA 92152-5001

PE: $0602233 \mathrm{~N}$

DN: 309119

WU: CDB8

C: N66001-96-D-0048

DO: 58

8. PERFORMING ORGANIZATION

REPORT NUMBER

TR 1815

9. SPONSORING/MONITORING AGENCY NAME(S) AND ADDRESS(ES)

Office of Naval Research

ONR 342

800 North Quincy Street

Arlington, VA 22217

11. SUPPLEMENTARY NOTES

12a. DISTRIBUTION/AVAILABILITY STATEMENT

Approved for public release; distribution is unlimited.

13. ABSTRACT (Maximum 200 words)

The use of three-dimensional (3-D) perspective views on flat screens for military command and control tasks is accelerating. The question is when and how to use these displays effectively. We report the results of three experiments to test the hypotheses that 3-D displays are useful for understanding object shape, but 2-D displays are more useful for understanding relative positions of objects. We tested this hypothesis using terrain stimuli. Participants viewed a 7- by 9-mile piece of terrain in 3-D from a 45-degree angle, a 90-degree angle, or in 2-D as a topographic map. In Experiment 1, participants chose the correct ground-level view from four alternatives. In Experiment 2, participants judged whether the position of one location was visible from another location or obstructed by intervening terrrain. In Experiment 3, participants judged which of two locations was higher. We found that participants were faster and more accurate in selecting the correct terrain shape with the 3-D views, but were more accurate in selecting the higher terrain location with the 2-D views.

\begin{tabular}{|l|l|} 
& $\begin{array}{c}\text { 15. NUMBER OF PAGES } \\
23\end{array}$ \\
\cline { 2 - 2 } & 16. PRICE CODE \\
\hline $\begin{array}{l}\text { 19. SECURITY CLASSIFICATION } \\
\text { OF ABSTRACT } \\
\text { UNCLASSIFIED }\end{array}$ & 20. LIMITATION OF ABSTRACT \\
SAME AS REPORT
\end{tabular}

Mission Area: human factors engineering man-machine interface three-dimensional display two-dimensional display virtual environments collaborative situation assessment

\begin{tabular}{l|l}
\hline $\begin{array}{l}\text { 17. SECURITY CLASSIFICATION } \\
\text { OF REPORT }\end{array}$ & $\begin{array}{l}\text { 18. SECURITY CLASSIFICATION } \\
\text { OF THIS PAGE } \\
\text { UNCLASSIFIED }\end{array}$ \\
UNCLASSIFIED
\end{tabular}




\section{INITIAL DISTRIBUTION}

$\begin{array}{ll}\text { D0012 } & \text { Patent Counsel } \\ \text { D0271 } & \text { Archive/Stock } \\ \text { D0274 } & \text { Library } \\ \text { D027 } & \text { M. E. Cathcart } \\ \text { D0271 } & \text { D. Richter } \\ \text { D301 } & \text { W. Wulfeck } \\ \text { D44207 } & \text { R. Yturralde } \\ \text { D44209 } & \text { G. Osga } \\ \text { D44209 } & \text { K. Van Orden } \\ \text { D44210 } & \text { M. Cowen } \\ \text { D44210 } & \text { H. Ko } \\ \text { D44210 } & \text { O. Larson } \\ \text { D44210 } & \text { J. Morrison } \\ \text { D44210 } & \text { R. Smillie }\end{array}$

(1)

Defense Technical Information Center

Fort Belvoir, VA 22060-6218

Naval Air Warfare Center

Weapons Divison

Point Mugu, CA 93042-5001

SSC San Diego Liaison Office

Arlington, VA 22202-4804

Naval Air Force U.S. Pacific Fleet

San Diego, CA 92135-7051

Center for Naval Analyses

Alexandria, VA 22302-0268

Navy Acquisition, Research and

Development Information Center

Arlington, VA 22202-3734

Government-Industry Data Exchange

Program Operations Center

Corona, CA 91718-8000

Navy Personnel Research and

Development Center

San Diego, CA 92152-7250

Office of Naval Research

Arlington, VA 22217-5660

Pacific Science and Engineering Group

San Diego, CA 92122

Space and Naval Warfare Systems Command

San Diego, CA 92110-3127

Fleet Antisubmarine Warfare Training Center

San Diego, CA 92147-5199

Naval Air Warfare Center

Training Systems Division

Orlando, FL 32826-3224

University of California, Santa Barbara

Santa Barbara, CA 93106

Instructional Science and Development, Inc.

Pensacola, FL 32507

University of Illinois

Champaign, IL 61820

Research Triangle Institute

Research Triangle Park, NC 27709 